\title{
MITI's research arm changes tack
}

Tokyo. Japan's Agency of Industrial Science and Technology (AIST), the main research arm of the powerful Ministry of International Trade and Industry (MITI), has introduced a new policy that gives greater freedom to its 15 institutes in selecting individual research projects.

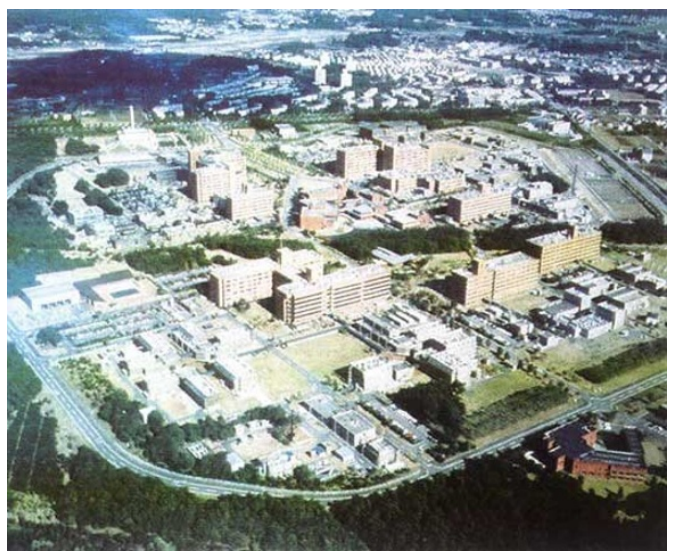

AIST's Tsukuba institutes: major centres favour MITI's change of emphasis.

The move is unprecedented for Japan, where a web of government bureaucracy runs throughout the government research system, and government officials cling jealously to their decision-making powers.

In general, AIST's larger institutes have welcomed the greater autonomy they are being offered. But some of the smaller ones are hesitating to accept the greater responsibility involved, fearing that they could lose out to more powerful colleagues.

The new policy was agreed last September, and described to the heads of the agency's institutes on 16 July by Hiroshi Kashiwagi, the recently appointed directorgeneral of AIST. (Kashiwagi was previously head of the agency's Electrotechnical Laboratory in Tsukuba.)

From the beginning of the current fiscal year, which started in April, special research funds known as tokubetsu kenkyuhi are being set aside by AIST for the institutes to spend as they choose, rather than having to seek prior approval by the agency.

So far, the amount of money involved is not very large, amounting to about $¥ 2.8$ billion ( $\$ 27$ million) for all 15 institutes. Once personnel costs have been excluded, this represents on average about 10 per cent of their research funds. But Kashiwagi hopes eventually to double this figure to 20 per cent, a move that would both give greater autonomy to the institutes, and introduce an element of competition between them.

Under the new system, all the institutes put forward proposals for the use of the special funds. The proposals are subse-

\section{Japan's low-profile 'centres of excellence'}

Tokyo. Japan's Science and Technology Agency (STA) unveiled on Monday three 'centres of excellence', to which it will give roughly an extra $\$ 20$ million over the next five years. The purpose is to raise the status of the institutions to that of Britain's Medical Research Council Laboratory of Molecular Biology at Cambridge or France's Institut Pasteur. But the world's scientists could be forgiven for never having heard of the three institutes selected.

The three lucky winners are:

STA's National Institute for Research in Inorganic Materials in Tsukuba science city, which will study new materials made at 1 10 million atmospheres pressure in the world's most powerful diamond press;

- The newly established National Institute of Bioscience and Human Technology of the Ministry of Trade and Industry, also in Tsukuba, which will carry out a broad range of research on signal transduction in humans (see Nature 364, 471; 1993);

- The National Cardiovascular Center Research Institute in Osaka, which will investigate the molecular mechanisms controlling the human circulatory system.
About 20 government institutes from science-related ministries and agencies vied for the first of the new awards introduced this fiscal year. Few details have been given of the procedure used to select the three winners. According to an STA official, each ministry and agency put forward several candidates that were then screened by the "policy committee" (seisaku iinkai) of the Council of Science and Technology. The council, nominally Japan's principal science policy-making body, is chaired by the prime minister and draws on the advice of academics, industrialists and civil servants in its various committees.

One criterion was how many papers an institute had published in international journals. STA also considers it important that the centres of excellence should attract scientists worldwide. But none of the institutes chosen has an outstanding publication record, nor are they as renowned outside Japan as some of the other institutes that were not chosen; no foreign scientists were consulted in the selection process.

David Swinbanks quently evaluated by a committee made up of the heads of the 15 institutes' planning sections, which decides how the funds will be allocated.

The chairman of this committee is the head of the research administration division of AIST. But whereas in the past all decisions about which proposals received funding were taken by AIST officials, the chairman's role in the new regime now is simply

\section{Trying to be more international}

Tokyo. The new policy to revitalize the institutes of the Agency of Industrial Science and Technology (AIST) also demands greater internationalization. Calls to open up government research are nothing new, but the agency has for the first time committed itself to an ambitious increase in the proportion of foreign researchers. The proposed increase, from 5 to 20 per cent, would add some 300 foreign researchers to the roughly 2,000 now working in the agency's 15 institutes.

The aim is not only to create more fellowships for foreign scientists but also to provide more permanent positions, says Tadatsuna Koda, director-general of the general coordination division of AIST. Most foreign researchers in AIST laboratories are employed on one to two year postdoctoral fellowships. AIST will find it difficult to achieve this, however: visa regulations are restrictive, international schools for children are few, spouses have poor prospects of finding jobs, and language barriers are formidable.

AIST also wants its institutes to publish more in international science journals. Even its best institutes perform poorly compared with equivalents in other countries. For example, the government this week chose as a 'centre of excellence' (see Nature 364 471 ; 1993) the National Institute of Bioscience and Human Technology which was formed earlier this year from the Fermentation Research Institute (FRI) and two other AIST institutes. But FRI's 70 researchers published only about 60 papers in international journals in 1992, fewer than one paper per researcher. This compares with around two per researcher per year at Korea's leading research universities, the Pohang Institute of Science and Technology and the Korea Institute of Science and Technology (see Nature 364, 379; 1993). 